\title{
Characterization of Yttrium-Rich Precipitates in a Titanium Alloy Weld
}

\author{
R. Prakash Kolli ${ }^{1, *}$, Andrew A. Herzing ${ }^{2}$, and Sreeramamurthy Ankem ${ }^{1}$ \\ ${ }^{1}$ Department of Materials Science and Engineering, University of Maryland \\ College Park, MD 20742, USA \\ ${ }^{2}$ Materials Measurement Science Division, National Institute of Standards and Technology \\ Gaithersburg, MD 20899, USA
}

*Corresponding Author: R. Prakash Kolli

Address: Department of Materials Science and Engineering

2144 Chemical and Nuclear Engineering Building, \#090

University of Maryland

College Park, MD 20742-2115, USA

E-mail: pkolli@umd.edu

Phone Number: 301-405-5217

Fax Number: 301-405-6327

\begin{abstract}
The yttrium-rich (Y-rich) precipitates that form in the fusion zone (FZ) of a Ti-5Al-1Sn-1Zr$1 \mathrm{~V}-0.8 \mathrm{Mo}$ (wt.\%) alloy, or Ti-5111, gas-tungsten arc welds (GTAW) were characterized. The filler metal was modified by a small concentration of $\mathrm{Y}$ in order to refine the microstructure and thus improve the FZ ductility. A high number density of nanoscale Y-rich precipitates were characterized in the weld FZ by atom probe tomography (APT) and scanning transmission electron microscopy (STEM).
\end{abstract}


Revision Submitted to Mater. Charac.

Keywords: Titanium; weld; yttrium; atom probe tomography (APT); high-angle annular dark field (HAADF) 
Revision Submitted to Mater. Charac.

\section{Introduction}

Titanium (Ti) alloys are technologically important for diverse applications in many industries, such as aerospace, biomedical, naval, and energy production [1,2]. One titanium alloy designed for structural marine applications is $\mathrm{Ti}-5 \mathrm{Al}-1 \mathrm{Sn}-1 \mathrm{Zr}-1 \mathrm{~V}-0.8 \mathrm{Mo}$ (wt.\%), which is referred to as Ti-5111 [3]. It has intermediate strength, excellent corrosion resistance, high toughness, excellent stress-corrosion cracking resistance, and room temperature creep resistance [3]. This alloy has a near- $\alpha$ microstructure that consists of colonies of hexagonal close-packed (h.c.p.) $\alpha$-phase plates (or lamella) with small quantities of retained body-centered cubic (b.c.c.) $\beta$-phase grains between the plates [4,5]. The h.c.p. $\alpha$-phase colonies have an orientation relationship (OR) such that their $\{0001\}$ basal planes are misoriented by $60^{\circ}$ and share a common $\langle 11 \overline{2} 0\rangle$ close-packed direction [5]. One limitation of this alloy is, however, that conventional welding processes may have a deleterious effect on the weld's ductility due to the embrittling effect of interstitial impurity elements, such as oxygen $(\mathrm{O})$ [6,7], and the formation of coarse, columnar grains in the fusion zone (FZ) microstructure [8]. Oxygen atoms reside at the octahedral interstitial sites of the h.c.p. $\alpha$-Ti lattice and act to strengthen the alloy thereby reducing its ductility and increasing its strength $[6,7,9]$. One approach to improve the weld ductility of alloys is microstructural refinement and sequestering of interstitial elements through compositional changes in the FZ by adding rare earth elements to the weld filler metal [10]. More specifically, Neuberger, et al.'s recent approach to improve the FZ ductility was to modify the weld filler metal by adding small concentrations of yttrium (Y) [11].

In earlier reported results, Neuberger, et al. [11] compared the mechanical properties and microstructure of Ti-5111 plates welded by filler metal matching the base metal (BM) composition, filler metal modified with 60 parts per million (ppm) Y, and filler metal modified 
Revision Submitted to Mater. Charac.

with 268 ppm Y when employing a gas-tungsten arc welding (GTAW) procedure. Their results indicated that the FZ of both yttrium-modified filler metal welds exhibited greater ductility (percent reduction in area) of $21.2 \pm 1.0 \%$ and $17.4 \pm 6.4 \%$, when compared to the the FZ of the matching BM filler metal weld ductility of $14.8 \pm 7.5 \%$ and the BM ductility of $15.0 \pm 3.3 \%$ [11,12]. Additionally, Vickers microhardness measurements indicated that the FZ of both yttrium-modified filler metal welds exhibited a lower hardness when compared to the FZ of the matching BM filler metal weld $[11,12]$. They also measured an improved tearing modulus, $T$, meaning that the FZ of both yttrium-modified filler metal welds exhibited more stable crack growth once a crack was initiated. Furthermore, their scanning electron microscope (SEM) observations of the fractured tensile specimens indicated that both yttrium-modified filler metal FZ fracture surfaces were more characteristic of failure by microvoid coalescence and dimpled rupture, whereas the matching $\mathrm{BM}$ filler metal $\mathrm{FZ}$ fracture surface was more characteristic of cleavage failure [11,12]. Neuberger, et al. partially attributed this improved response to a smaller average grain diameter in the FZ of both yttrium-modified filler metal welds caused by the possible presence of Y-rich precipitates that inhibited columnar grain growth and promoted limited heterogeneous nucleation of the grains $[11,12]$. Their conventional transmission electron microscope (TEM) and selected area electron diffraction (SAED) pattern observations suggested the presence of small nanoscale precipitates in the FZ of the yttrium-modified filler metal welds that were not present in the FZ of the matching BM filler metal welds [11,12]. The crystal structure of the small precipitates could not, however, be definitively resolved, and their composition was not conclusively characterized. The authors suggested, however, that the precipitates were possibly face-centered cubic (f.c.c.) yttrium oxide $\left(\mathrm{Y}_{2} \mathrm{O}_{3}\right)$ or trigonal yttrium oxysulfide $\left(\mathrm{Y}_{2} \mathrm{O}_{3} \mathrm{~S}\right)$ based on the aforesaid observations and due to the strong affinity between $\mathrm{Y}$ 
Revision Submitted to Mater. Charac.

and $\mathrm{O}$ or $\mathrm{S}$ that is related to their electronic structure leading to large negative values of enthalpy of formation, $\Delta \mathrm{H}_{\mathrm{f}}$, and even small concentrations can lead to the formation of oxides and sulfides $[10,13,14]$.

This investigation characterizes the possible Y-rich precipitates that form in the FZ of the high yttrium-modified filler metal weld, which improve its ductility. We employ state-of-the-art atom probe tomography (APT) and scanning transmission electron microscopy (STEM) and report the first direct visualization of these precipitates and confirm that they are enriched in $\mathrm{Y}$. The sub-nanometer spatial resolution and high elemental sensitivity of the APT technique [15] permits three-dimensional (3-D) visualization of nanoscale precipitates [16], while STEM permits analysis of a wider field-of-view (FOV) than APT via both high-angle annular dark-field (HAADF) imaging and x-ray energy dispersive spectroscopy (XEDS). We also discuss the local distribution of $\mathrm{O}$ and $\mathrm{S}$ in the weld FZ matrix phase and the Y-rich precipitates.

\section{Experimental Procedures}

\subsection{Material}

The nominal composition of the yttrium-modified filler metal containing $268 \mathrm{ppm} \mathrm{Y}$ and the base metal as measured by Timet Co. are given in Table 1. Details regarding the BM alloy plate fabrication and yttrium-modified filler metal fabrication are found in Refs. [11,12]. The BM had a nominal thickness of approximately $25.4 \mathrm{~mm}$ (1-inch). A summary of the GTAW procedure is presented here and additional details are also found in Refs. [11,12]. Welding was performed by Tricor Metals, Inc. The double-V butt weld joint was fabricated by GTAW inside a glove box using nominally pure (> 99.99 at.\%) argon (Ar) shielding gas. A total of 12 weld 
Revision Submitted to Mater. Charac.

passes were performed on each side using a nominal arc voltage of $\sim 15$ volts (V), a nominal weld current of 225 amps (A), and a travel speed of $3.4 \mathrm{~mm} \mathrm{~s}^{-1}$ for each pass.

\subsection{Atom Probe Tomography (APT)}

Specimens with a needle-shaped geometry necessary for APT analysis were fabricated using a FEI $^{1}$ Nova 600 dual-beam scanning electron microscope/focused ion beam (SEM/FIB) instrument following standard lift-out and annular milling procedures $[17,18]$. The in situ sitespecific specimen preparation technique was performed on metallographic mounts to take APT specimen blanks in the weld FZ. Details regarding fabrication of the mounts are presented in Refs. [11,12]. A platinum (Pt) protective layer was deposited over a region of interest (ROI) using established procedures. Annular milling was performed employing a $30 \mathrm{keV}$ gallium ion $\left(\mathrm{Ga}^{+}\right)$beam and sequentially decreasing probe current following standard procedures after transfer of the ROI to silicon ( $\mathrm{Si}$ ) microtip posts with an Omniprobe Micromanipulator [19]. A low keV ion beam of $5 \mathrm{keV}$ was allowed to raster over the specimen tip to remove material that had been damaged by the $30 \mathrm{keV} \mathrm{Ga}^{+}$ion beam annular milling operation [20]. The final apex of the specimen tips had a radii of $\sim 50 \mathrm{~nm}$ suitable for APT analysis.

A CAMECA Local-Electrode Atom Probe $\left(\right.$ LEAP $\left.^{\circledR}\right) 4000$ instrument in the Si configuration was used to perform pulsed-voltage APT. Data acquisition was performed at a specimen tip base temperature of $70 \mathrm{~K}$, a pulse frequency of $200 \mathrm{kHz}$, and a pulse-to-standing DC voltage ratio of $20 \%$ in order to promote field evaporation. The evaporation rate was maintained at a constant $0.5 \%$ or 0.005 ions per pulse. The background pressure was an ultra-

${ }^{1}$ Certain commercial equipment, instruments, or materials are identified in this paper in order to specify the experimental procedure adequately. Such identification is not intended to imply recommendation or endorsement by the National Institute of Standards and Technology, nor is it intended to imply that the materials or equipment identified are necessarily the best available for the purpose. 
Revision Submitted to Mater. Charac.

high vacuum $(\mathrm{UHV})$ of $1.1 \times 10^{-8} \mathrm{~Pa}\left(8.1 \times 10^{-11}\right.$ Torr). Data reconstruction and analysis was performed using the CAMECA Integrated Visualization and Analysis Software (IVAS), version 3.6.6.

\subsection{Scanning Electron Transmission Microscopy (STEM)}

Specimens taken from the weld FZ were also prepared for analysis by STEM-HAADF imaging and XEDS elemental characterization using standard dual-beam SEM/FIB instrument lift-out techniques [21]. Analysis was performed using an FEI Titan 80-300 STEM operating at $300 \mathrm{kV}$ and a probe current of approximately $0.1 \mathrm{nA}$. For XEDS analysis, the microscope was also equipped with an EDAX Sapphire r-TEM side-entry $\mathrm{Si}(\mathrm{Li})$ spectrometer with super ultra thin window, a nominal solid angle of collection of 0.1 steradians, an energy resolution of 134 $\mathrm{eV}$ as measured for the $\mathrm{Mn}-\mathrm{K}_{\alpha} \mathrm{X}$-ray peak, and an active detector area of $30 \mathrm{~mm}^{2}$. The XEDS hyperspectral images were acquired using a higher probe current of $0.3 \mathrm{nA}$ from a $300 \mathrm{~nm} \times 250$ $\mathrm{nm}$ area of the specimen that contained several precipitates. A $5 \mathrm{~nm} \times 5 \mathrm{~nm}$ pixel size was used and the spectra were integrated for $1 \mathrm{~s}$. Phase analysis was performed using the Sandia National Laboratory (SNL) Automated eXpert Spectral Image Analysis (AXSIA) multivariate statistical analysis software [22], and spectral analysis was performed using the National Institute of Standards and Technology (NIST) Desk Top Spectrum Analyzer (DTSA) II software [23].

\section{Results and Discussion}

\subsection{Yttrium-rich (Y-rich) Precipitates}

The APT reconstruction, Fig. 1(a), illustrates nanoscale spheroidal Y-rich particles (red isoconcentration surfaces) that are distributed in the weld FZ matrix phase (blue atoms) with a 
high number density, $N_{V}$, of ca. $3.0 \times 10^{24}$ particles $\mathrm{m}^{-3}$, where the theoretical atomic density is ca. 42.5 atom $\mathrm{nm}^{-3}$ for this $\mathrm{Ti}$ alloy, which is used to determine the volume. The FZ contains predominantly Ti atoms (blue), as discussed below. These particles have a mean spherical volume equivalent radius, $\langle r\rangle=0.85 \pm 0.05 \mathrm{~nm}$, where the $\pm 2 \sigma$ error is given by standard error of the mean and the spheroid volumes are provided by interface analysis in the IVAS software. A normal probability plot, Fig. 1(b), demonstrates that these particles deviate from linearity that is expected of local statistical compositional fluctuations in a random solid-solution and thus these particles are stable Y-rich precipitates. Correlative STEM-HAADF imaging accompanied with XEDS elemental analysis was also performed in order to visualize the Y-rich precipitates in the weld FZ. The STEM-HAADF image in Fig. 2(a) illustrates nanoscale spheroidal areas of lighter phase contrast several of which are highlighted by black circles in a matrix of darker phase contrast that further demonstrates precipitates are distributed in the FZ microstructure. The observed contrast variation is indicative of differences in atomic masses, i.e. Z-contrast. A higher magnification view of an ROI (yellow square) encompassing a subset of the STEMHAADF image in Fig. 2(a) also illustrates the nanoscale spheroidal precipitates, Figs. 2(b). An accompanying parallel STEM-XEDS data image illustrates that these are Y-rich precipitates (red) in the weld FZ (blue), Fig. 2(c). The accompanying XEDS spectra for the precipitates (red), Figs. 2(d) - (e), exhibits a $\mathrm{Y}-\mathrm{K}_{\alpha}$ peak at $14.931 \mathrm{keV}$ and a $\mathrm{Y}-\mathrm{L}_{\alpha}$ peak at $1.922 \mathrm{keV}$, whereas the weld FZ (blue) does not exhibit a Y signal greater than the background noise. Thus, a second independent visualization technique, which is based on Z-contrast imaging, also illustrates that Y-rich precipitates exist in the weld FZ after the welding process.

Compositional analysis using proximity histogram (proxigram) [24,25] concentration profiles, Figs. 3(a) - (c), illustrate the distribution of Ti (blue circles), Al (teal inverted triangles), 
Revision Submitted to Mater. Charac.

Y (red diamonds), Sn (mustard triangles), Zr (green inverted triangles), V (gray circles), and Mo (purple squares) atoms in the FZ matrix phase and the precipitates. The $\mathrm{O}$ and $\mathrm{S}$ (light blue circles) concentration profile is also depicted in Fig. 2(b) and discussed below. The enhancement of Y in Fig. 2(b) permits discrimination of the precipitates at the right-hand side of the Ti matrix/Y-rich precipitate heterophase interfaces. Quantitative analysis of the precipitate and weld FZ Ti-matrix phase compositions are derived from the APT proxigram concentration profiles, Table 2. In this investigation, the plateau points within the matrix (far-field) yield the FZ Ti-matrix concentrations where the plateau points [26] are delineated by utilizing the Ti concentration profile as a fiducial marker. Only data points within the flat region of the profile, a minimum of $1.0 \mathrm{~nm}$ away from the heterophase interfaces and with $\pm 2 \sigma<0.2$ at.\%, are included as plateau points. We consider here that the seven right-hand side points from the interfaces in Figs. 3(a) - (c) delineate the precipitate compositions. The partitioning ratio for an element $i$ is defined as $\kappa_{i}^{\text {ppt. } / \text { mat. }}=C_{i}^{\text {ppt. }} / C_{i}^{\text {mat.,ff }}$, where $C_{i}^{\text {ppt. }}$ is the precipitate composition and $C_{i}^{\text {mat.,ff }}$ is the far-field matrix concentration. The calculated partitioning ratios from the results in Table 2 are 0.98 for Ti, 1.04 for $\mathrm{Al}, 50.0$ for $\mathrm{Y}, 1.0$ for $\mathrm{Zr}, 0.9$ for $\mathrm{V}, 0.8$ for Mo, and 1.0 for Sn. The observed precipitates are strongly enriched in Y. The Y-rich precipitates are slightly depleted in V and Mo. Titanium exhibits a very small depletion while Al exhibits a very small enrichment in the Y-rich precipitates relative to the FZ $\alpha$-Ti matrix. Yttrium exhibits limited solid-solubility in $\mathrm{Ti}$, and its maximum solubility in h.c.p. $\alpha-\mathrm{Ti}$ is significantly $<1$ at. $\%$ at temperatures $\leq 870$ ${ }^{\circ} \mathrm{C}$ [27]. Hence, it is possible that the Y-rich precipitates nucleate and grow by solid-state transformation during air-cooling of the weld FZ after completion of the welding process. The APT proxigram analysis of the precipitates illustrate that they are enriched in Y but also contain concentrations of $\mathrm{Ti}, \mathrm{Al}, \mathrm{Zr}, \mathrm{V}, \mathrm{Mo}, \mathrm{Sn}$, and $\mathrm{O}$ that are similar to that present in the weld $\mathrm{FZ}$ 
Revision Submitted to Mater. Charac.

matrix, Table 2. It is known, however, that precipitates with a radius of $<\sim 1 \mathrm{~nm}$ may be influenced by elements from the matrix phase due to trajectory overlap and local magnification effects [28]. Hence, this limitation may prevent determination of the exact composition of the precipitates.

\subsection{Oxygen and Sulfur}

The nominal composition of $\mathrm{O}$ is 0.094 wt.\% in the BM and 0.089 wt.\% in the high-Y weld filler metal and $\mathrm{S}$ is present as a trace element and thus these elements are expected in the weld FZ. Wavelength dispersive spectroscopy (WDS) results indicated that both $\mathrm{O}$ and $\mathrm{S}$ are present in the weld FZ in Refs. [11,12]. In an APT mass spectrum, $\mathrm{O}, \mathrm{O}_{2}$, and $\mathrm{S}$ are, however, convoluted at a mass-to-charge state $(\mathrm{m} / \mathrm{n})$ ratio of 16 and also at a $(\mathrm{m} / \mathrm{n})$ ratio of 32 and thus the two elements are not readily distinguishable. Furthermore, the XEDS spectra could not delineate the presence of one element or the other due to convolution of the $\mathrm{O}-\mathrm{K}_{\alpha}$ peak at 0.523 $\mathrm{keV}$ with the $\mathrm{Ti}-\mathrm{L}_{\alpha}$ peak at $0.452 \mathrm{keV}$ and the $\mathrm{V}-\mathrm{L}_{\alpha}$ peak at $0.510 \mathrm{keV}$, and the convolution of the $\mathrm{S}-\mathrm{K}_{\alpha}$ peak at $2.307 \mathrm{keV}$ with the $\mathrm{Mo}-\mathrm{L}_{\alpha}$ peak at $2.293 \mathrm{keV}$. Hence, we assume that both elements may be present in the following discussion of the APT results.

The proximity histogram concentration profile in Fig. 1(b) illustrates that $\mathrm{O}$ and $\mathrm{S}$ are present in the weld FZ $\alpha$-Ti matrix at a concentration of $0.3 \pm 0.1$ at. $\%$ and in the Y-rich precipitates at a concentration of $0.3 \pm 0.03$ at. $\%$, Table 2 . The calculated partitioning ratio is 1.0 indicating that $\mathrm{O}$ and $\mathrm{S}$ are equally present in the $\mathrm{Y}$-rich precipitates and the weld $\mathrm{FZ} \alpha-\mathrm{Ti}$ matrix. The proxigram concentration profiles indicate, however, that local variation exists, particularly in the Y-rich precipitates and at the heterophase interfaces. A small O peak of $0.6 \pm$ 0.2 at.\% is located at a distance of $0.25 \mathrm{~nm}$ from the heterophase interfaces in the proxigram 
concentration profiles. A second small peak of $0.4 \pm 0.3$ at.\% is located at a distance of $0.45 \mathrm{~nm}$ from the heterophase interfaces. A depletion of $0.1 \pm 0.05$ at.\% is located at a distance of -0.05 $\mathrm{nm}$ from the heterophase interfaces. Hence, in order to examine the distribution of $\mathrm{O}$ and $\mathrm{S}$ relative to $\mathrm{Y}$ in the $\mathrm{FZ} \alpha$-Ti matrix and Y-rich precipitates, we perform a concentration profile analysis of these elements averaged along the length of a $2 \mathrm{~nm}$ diameter cylinder with $1 \mathrm{~nm}$ bins at two different example locations in the reconstruction in Fig. 1(a). The concentration profiles illustrate visible enhancements of $\mathrm{Y}$ (red triangles) in each profile, Figs. 4(a) - (b), that correspond to Y-rich precipitates in Fig. 1(a). The $\mathrm{O}$ and $\mathrm{S}$ (light blue circles) profile illustrates that the local concentrations of these elements fluctuate in the FZ $\alpha-\mathrm{Ti}$ matrix. Oxygen and $\mathrm{S}$ are also present in the Y-rich precipitates and at the $\mathrm{FZ} \alpha-\mathrm{Ti}$ matrix/Y-rich precipitate heterophase interfaces. The local $\mathrm{O}$ and $\mathrm{S}$ concentration at the interfaces is slightly greater than in the precipitates as demonstrated by the $\sim 0.68$ at. $\%$ and $\sim 0.69$ at.\% peaks relative to the $\sim 0.38$ at. $\%$ concentration in the Y-rich precipitate in Fig. 4(a); and similarly, the $\sim 0.94$ at.\% and $\sim 0.90$ at.\% $\mathrm{O}$ and $\mathrm{S}$ peaks relative to the $\sim 0.27$ at.\% concentration in the Y-rich precipitate in Fig. $4(\mathrm{~b})$. The observed variability and fluctuations of $\mathrm{O}$ and $\mathrm{S}$ in the FZ $\alpha$-Ti matrix are most likely due to the natural heterogeneity of the weld FZ microstructure [11,12] combined with non-equilibrium kinetics that occurs during welding and cooling. Differences in solidification rates and cooling rates during the welding process can lead to local heterogeneity in the microstructure and also varying time intervals for the effective diffusivity thereby leading to local variations and fluctuations in the $\mathrm{O}$ and $\mathrm{S}$ concentrations. 


\section{Conclusion}

Atom probe tomography and STEM-HAADF imaging accompanied with XEDS elemental characterization were employed to characterize the Y-rich precipitates that improve the ductility of the weld FZ in a Ti-5111 alloy. The weld was fabricated by the GTAW procedure using filler metal modified with a small concentration of $\mathrm{Y}$. This investigation resulted in the following findings:

(1) A high number density, $N_{V}$, of ca. $3.4 \times 10^{24}$ precipitates $\mathrm{m}^{-3}$, of spheroidal Y-rich precipitates with a mean radius, $\langle r\rangle$, of $0.85 \pm 0.05 \mathrm{~nm}$ were observed distributed in the FZ $\alpha$-Ti matrix by APT. The calculated partitioning ratio of $\mathrm{Y}$ is 50.0 illustrating significant enhancement of $\mathrm{Y}$ in the precipitates.

(2) Nanoscale spheroidal Y-rich precipitates were also observed distributed in the FZ $\alpha-$ Ti matrix by Z-contrast imaging accompanied with XEDS elemental analysis.

(3) The $\mathrm{O}$ and $\mathrm{S}$ concentrations exhibit local fluctuations in the FZ $\alpha$-Ti matrix and are also present in the $\mathrm{Y}$-rich precipitates and at the $\alpha$-Ti matrix/Y-rich precipitate heterophase interfaces. 
Revision Submitted to Mater. Charac.

\section{Acknowledgements}

The authors would like to thank Dr. Frederick Meisenkothen and Mr. Eric B. Steel for access to the Local Electrode Atom Probe $\left(\right.$ LEAP $\left.^{\circledR}\right)$ instrument at the National Institute of Standards and Technology (NIST) in Gaithersburg, MD. Dr. Frederick Meisenkothen is also thanked for reviewing the manuscript. The authors would also like to thank Dr. Brett W. Neuberger for coordinating the welding procedure, fabrication of metallographic specimens, and performing mechanical property testing. 
Revision Submitted to Mater. Charac.

\section{References}

[1] C. Leyens, M. Peters, eds., Titanium and Titanium Alloys, Wiley-VCH GmbH \& Co., Weinheim, Germany, 2006.

[2] D. Banerjee, J.C. Williams, Perspectives on Titanium Science and Technology, Acta Mater. 61 (2013) 844-879. doi:10.1016/j.actamat.2012.10.043.

[3] J. Been, K. Faller, Using Ti-5111 for marine fastener applications, JOM. 51 (1999) 21-24. doi:10.1007/s11837-999-0088-5.

[4] R.P. Kolli, W.J. Joost, S. Ankem, Phase Stability and Stress-Induced Transformations in Beta Titanium Alloys, JOM. 67 (2015) 1273-1280. doi:10.1007/s11837-015-1411-y.

[5] K.E. Knipling, R.W. Fonda, Microstructural Evolution in Ti-5111 Friction Stir Welds, Metall. Mater. Trans. A. 42 (2011) 2312-2322. doi:10.1007/s11661-011-0630-2.

[6] M.L. Wasz, F.R. Brotzen, R.B. McLellan, A.J. Griffin, Effect of oxygen and hydrogen on mechanical properties of commercial purity titanium, Inter. Mater. Rev. 41 (1996) $1-12$.

[7] M. Yan, Y. Liu, G.B. Schaffer, M. Qian, In situ synchrotron radiation to understand the pathways for the scavenging of oxygen in commercially pure $\mathrm{Ti}$ and $\mathrm{Ti}-6 \mathrm{Al}-4 \mathrm{~V}$ by yttrium hydride, Scripta Mater. 68 (2013) 63-66. doi:10.1016/j.scriptamat.2012.09.024.

[8] M.C. Nordin, G.R. Edwards, D.L. Olson, The Influence of Yttrium Microadditions on Titanium Weld Metal Cracking Susceptibility and Grain Morphology, Weld. J. 66 (1987) $342 \mathrm{~s}-352 \mathrm{~s}$.

[9] H. Conrad, Effect of interstitial solutes on the strength and ductility of titanium, Prog. Mater. Sci. 26 (1981) 123-403. doi:10.1016/0079-6425(81)90001-3.

[10] E.A. Pfief, C. Howard, S. Tate, B. Mishra, D.L. Olson, Use of Segregation As A Weld Design Opportunity, in: Trends in Welding Research, Proceedings of the 9th International Conference, ASM International, Chicago, IL, 2012: pp. 11-18.

[11] B.W. Neuberger, P.G. Oberson, S. Ankem, The Effect of Yttrium on Ti-5111 Gas Tungsten Arc Welds, Metall. Mater. Trans. A. 42 (2011) 1296-1309. doi:10.1007/s11661-010-05328.

[12] B.W. Neuberger, Dynamics of Near-Alpha Titanium Welding, Ph.D., University of Maryland, 2004. http://drum.lib.umd.edu/handle/1903/1946 (accessed October 2, 2015).

[13] R.P. Simpson, Controlled Weld-Pool Solification Structure and Resultant Properties with Yttrium Inoculation of Ti-6Al-6V-2Sn Welds, Weld. J. 56 (1977) 67s - 77s.

[14] B. Poorganji, A. Kazahari, T. Narushima, C. Ouchi, T. Furuhara, Effect of yttrium addition on grain growth of $\alpha, \beta$ and $\alpha+\beta$ titanium alloys, J. Phys.: Conf. Ser. 240 (2010) 012170. doi:10.1088/1742-6596/240/1/012170.

[15] T.F. Kelly, D.J. Larson, Atom Probe Tomography 2012, Annu. Rev. Mater. Res. 42 (2012) 1-31. doi:10.1146/annurev-matsci-070511-155007.

[16] D. Isheim, R.P. Kolli, M.E. Fine, D.N. Seidman, An atom-probe tomographic study of the temporal evolution of the nanostructure of $\mathrm{Fe}-\mathrm{Cu}$ based high-strength low-carbon steels, Scripta Mater. 55 (2006) 35-40. doi:10.1016/j.scriptamat.2006.02.040.

[17] K. Thompson, D. Lawrence, D.J. Larson, J.D. Olson, T.F. Kelly, B. Gorman, In situ sitespecific specimen preparation for atom probe tomography, Ultramicrosc. 107 (2007) 131139. doi:10.1016/j.ultramic.2006.06.008.

[18] M.K. Miller, K.F. Russell, K. Thompson, R. Alvis, D.J. Larson, Review of Atom Probe FIB-Based Specimen Preparation Methods, Microsc. Microanal. 13 (2007) 428-436. doi:10.1017/S1431927607070845. 
[19] R.P. Kolli, F. Meisenkothen, A Focused Ion Beam Specimen Preparation Method to Minimize Gallium Ion Concentration in Copper Atom-Probe Tomography Specimen Tips, Microsc. Microanal. 20 (2014) 350-351. doi:10.1017/S143192761400347X.

[20] K. Thompson, B. Gorman, D. Larson, B. van Leer, L. Hong, Minimization of Ga Induced FIB Damage Using Low Energy Clean-up, Microsc. Microanal. 12 (2006) 1736-1737. doi:10.1017/S1431927606065457.

[21] L.A. Giannuzzi, B.W. Kempshall, S.M. Schwarz, J.K. Lomness, B.I. Prenitzer, F.A. Stevie, FIB Lift-Out Specimen Preparation Techniques, in: L.A. Giannuzzi, F.A. Stevie (Eds.), Introduction to Focused Ion Beams, Springer US, 2005: pp. 201-228. http://link.springer.com/chapter/10.1007/0-387-23313-X_10 (accessed November 10, 2013).

[22] P.G. Kotula, M.R. Keenan, J.R. Michael, Automated Analysis of SEM X-Ray Spectral Images: A Powerful New Microanalysis Tool, Microsc. Microanal. 9 (2003) 1-17. doi:10.1017/S1431927603030058.

[23] N.W.M. Ritchie, Desk Top Spectrum Analyzer II, National Institute of Standards and Technology, Gaithersburg, MD, 2015.

[24] O.C. Hellman, J.A. Vandenbroucke, J. Rüsing, D. Isheim, D.N. Seidman, Analysis of Three-Dimensional Atom-Probe Data by the Proximity Histogram, Microsc. Microanal. 6 (2000) 437-444.

[25] R.P. Kolli, D.N. Seidman, Comparison of Compositional and Morphological Atom-Probe Tomography Analyses for a Multicomponent Fe-Cu Steel, Microsc. Microanal. 13 (2007) 272-284. doi:10.1017/S1431927607070675.

[26] C.K. Sudbrack, D. Isheim, R.D. Noebe, N.S. Jacobson, D.N. Seidman, The Influence of Tungsten on the Chemical Composition of a Temporally Evolving Nanostructure of a Model Ni-Al-Cr Superalloy, Microsc. Microanal. 10 (2004) 355-365. doi:10.1017/S1431927604040589.

[27] B. Predel, Ti-Y (Titanium-Yttrium), in: O. Madelung (Ed.), Landolt-Börnstein - Group IV Physical Chemistry, Springer-Verlag, Berlin/Heidelberg, 1998: pp. 1-1. http://materials.springer.com/lb/docs/sm_lbs_978-3-540-70705-9_2844 (accessed March 30, 2016).

[28] F. Vurpillot, A. Bostel, D. Blavette, Trajectory overlaps and local magnification in threedimensional atom probe, Applied Physics Letters. 76 (2000) 3127-3129. doi:10.1063/1.126545. 
Revision Submitted to Mater. Charac.

\section{List of Tables}

Table 1. Nominal compositions of the Ti-5111 base metal (BM) and yttrium-modified weld filler metal as reported in Ref. [11].

\begin{tabular}{|c|c|c|c|c|c|c|c|c|c|c|}
\hline & & \multicolumn{8}{|c|}{ Elements } & \multirow[b]{2}{*}{$\mathrm{C}$} \\
\hline & & $\mathrm{Ti}$ & $\mathrm{Al}$ & $\mathrm{Y}$ & $\mathrm{Zr}$ & V & Mo & $\mathrm{Sn}$ & $\mathrm{O}$ & \\
\hline \multirow{2}{*}{$\begin{array}{l}\text { High-Y Weld } \\
\text { Filler Metal } \\
\text { (FM) }\end{array}$} & (wt.\%) & Balance & 4.40 & 0.0268 & 1.00 & 1.00 & 0.75 & 1.00 & 0.089 & - \\
\hline & (at.\%) & Balance & 7.70 & 0.014 & 0.51 & 0.92 & 0.37 & 0.40 & 0.261 & - \\
\hline \multirow{2}{*}{$\begin{array}{c}\text { Base Metal } \\
\text { (BM) }\end{array}$} & (wt.\%) & Balance & 4.92 & - & 1.05 & 1.00 & 0.80 & 1.00 & 0.094 & 0.009 \\
\hline & (at.\%) & Balance & 8.52 & - & 0.54 & 0.92 & 0.38 & 0.39 & 0.274 & 0.035 \\
\hline
\end{tabular}

Table 2. Composition (at.\%) of the nanoscale yttrium-rich (Y-rich) precipitates and the weld fusion zone (FZ) $\alpha$-Ti matrix as measured by atom probe tomography (APT).

\begin{tabular}{|c|c|c|c|c|c|c|c|c|}
\hline & \multicolumn{8}{|c|}{ Elements } \\
\hline & $\mathrm{Ti}$ & $\mathrm{Al}$ & $\mathrm{Y}$ & $\mathrm{Zr}$ & V & Mo & Sn & $\mathrm{O}$ \\
\hline $\begin{array}{l}\text { Y-rich } \\
\text { Precipitates' } \\
\text { Composition }\end{array}$ & $85.8 \pm 1.0$ & $8.8 \pm 0.7$ & $2.0 \pm 0.3$ & $0.5 \pm 0.1$ & $1.0 \pm 0.2$ & $0.4 \pm 0.1$ & $0.3 \pm 0.1$ & $0.3 \pm 0.1$ \\
\hline $\begin{array}{l}\text { Weld FZ Ti- } \\
\text { Matrix } \\
\text { Composition }\end{array}$ & $87.9 \pm 0.2$ & $8.5 \pm 0.2$ & $0.04 \pm 0.01$ & $0.5 \pm 0.03$ & $1.1 \pm 0.1$ & $0.5 \pm 0.04$ & $0.3 \pm 0.03$ & $0.3 \pm 0.03$ \\
\hline
\end{tabular}

Concentrations are in at.\%

Concentrations do not total to 100 at.\% due to rounding and the presence of $\mathrm{Nb}, \mathrm{C}$, and $\mathrm{N}$ trace and residual elements 


\section{List of Figures and Captions}

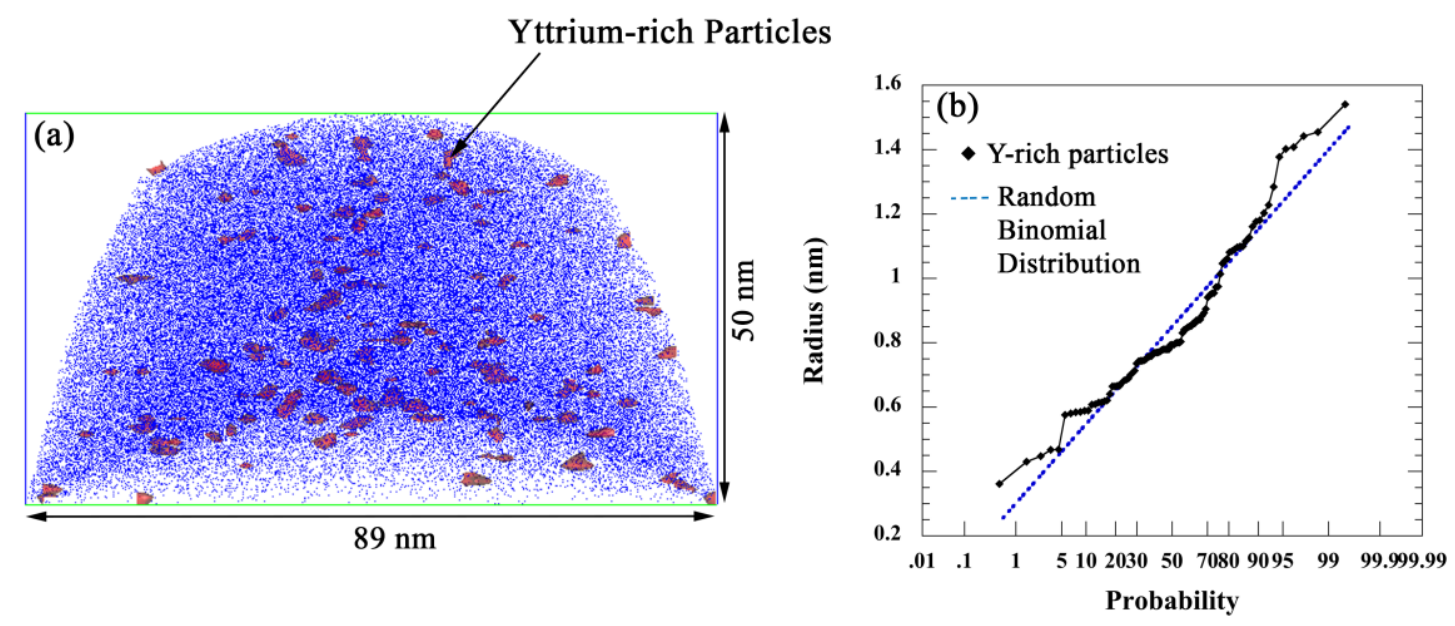

Figure 1. Atom probe tomography (APT) reconstruction illustrating (a) the nanoscale spheroidal yttrium-rich (Y-rich) particles delineated by 0.25 at.\% Y isoconcentration surfaces (red) in the weld fusion zone (FZ); and (b) the corresponding normal probability plot with a superimposed dashed line (blue) of a random binomial distribution. The reconstructed volume of $88 \mathrm{~nm} \times 89$ $\mathrm{nm} \times 50 \mathrm{~nm}$ in (a) contains approximately 7.3 millions ions. Only Y (red) and ca. $2.3 \%$ of the Ti (blue) atoms are shown for clarity in (a). The remaining elements are not shown for clarity. 

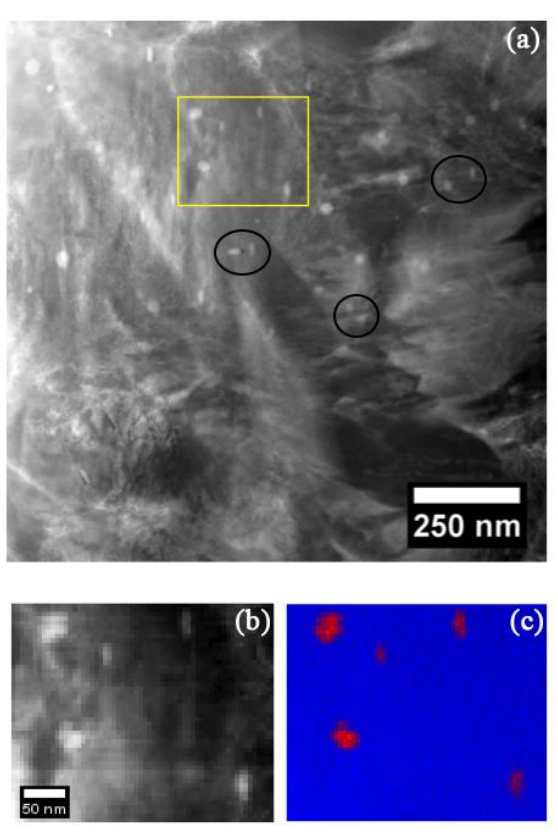

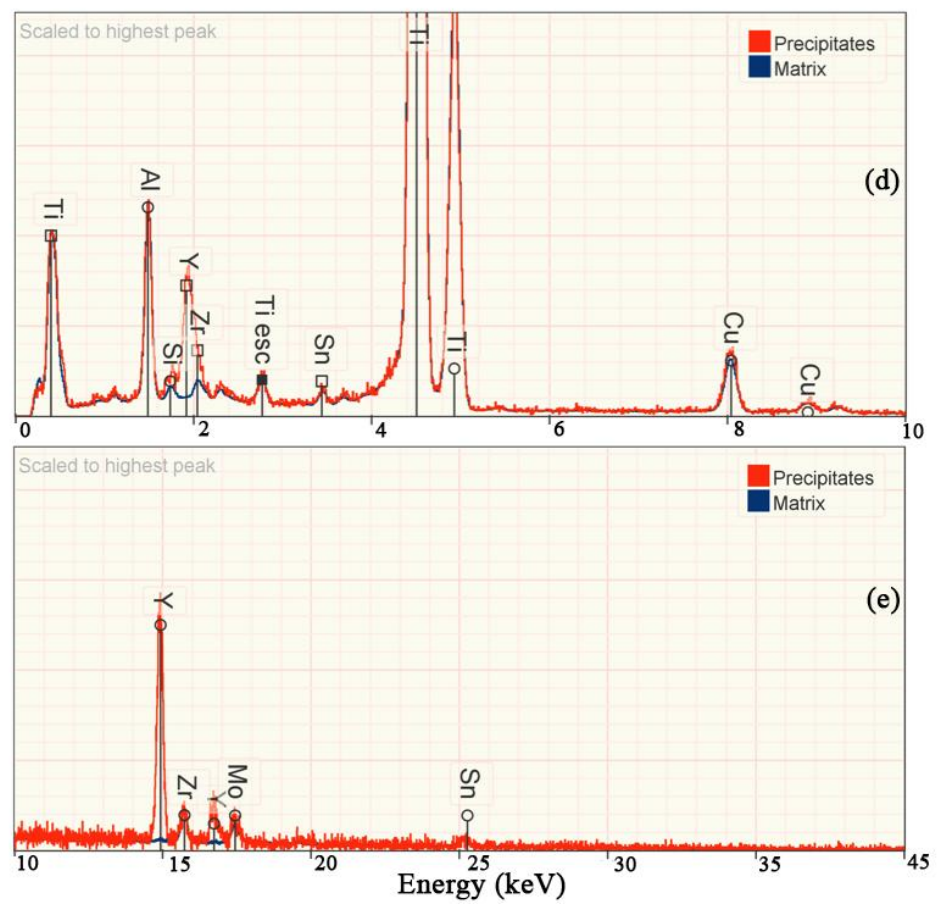

Figure 2. Results of STEM analysis of the fusion zone (FZ) illustrating a STEM-HAADF image of the distribution of Y-rich precipitates in the FZ several of which are delineated by black circles, and a sub-region (yellow rectangle) analyzed by XEDS in (a). Depicted are the real-time HAADF output in (b) acquired simultaneously with the STEM-XEDS data in (c) that illustrates the spatial extent of the precipitate phase (red) and weld FZ matrix phase (blue) identified by multivariate statistical analysis. The accompanying XEDS spectra for the precipitates (red) and FZ matrix phase (blue) are shown in (d) and (e). For clarity, the spectral components are shown in two separate panels, one spanning between $0 \mathrm{keV}$ and $10 \mathrm{keV}$ and the other between $10 \mathrm{keV}$ and $40 \mathrm{keV}$. The $\mathrm{Cu}$ peaks are due to the specimen holder. 
Revision Submitted to Mater. Charac.
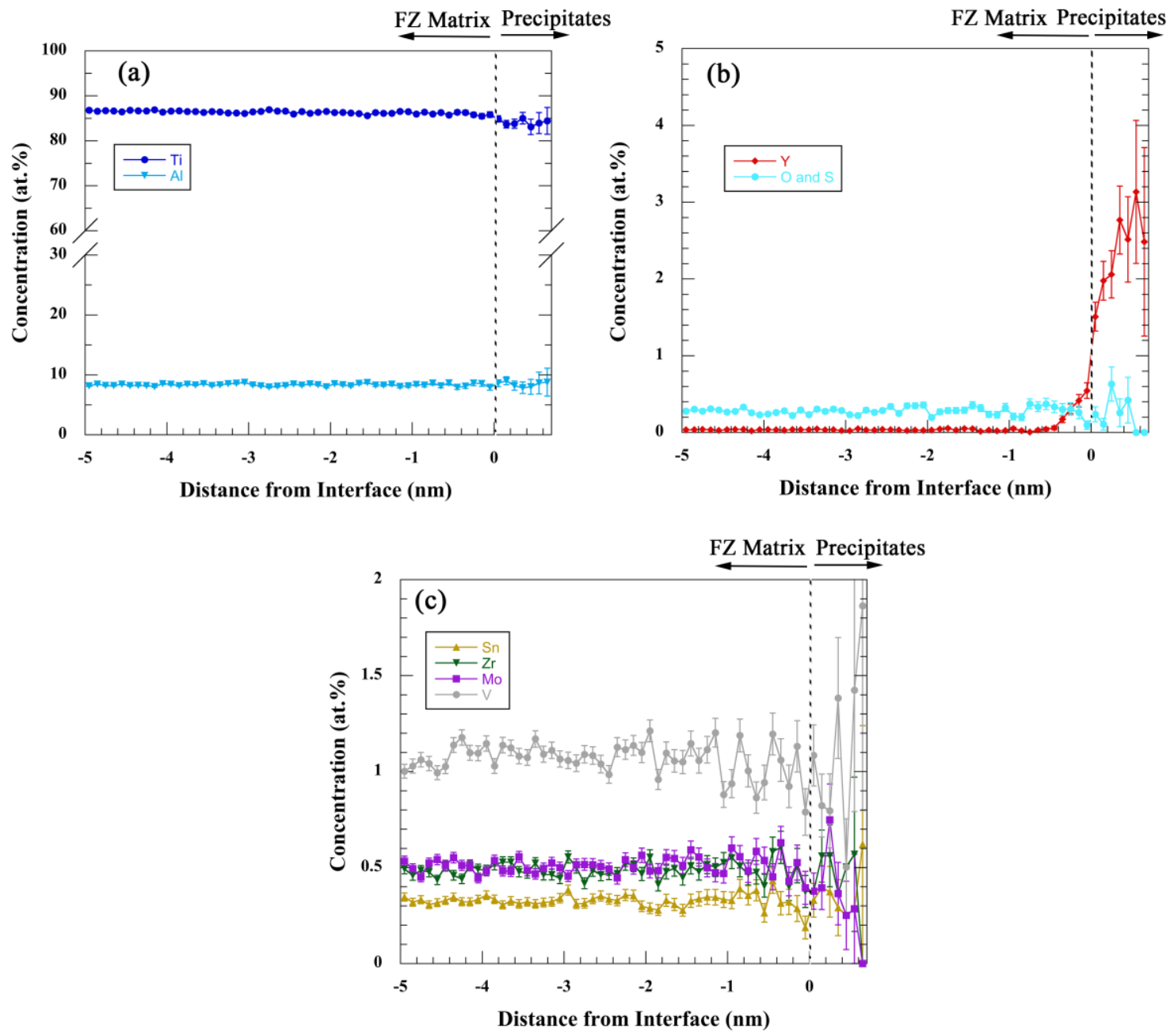

Figure 3. The proximity histogram concentration profiles (at.\%) derived from the reconstruction in Fig. 1(a) illustrating (a) Ti (blue circles) and $\mathrm{Al}$ (teal upside down triangles); (b) Y (red diamonds) and $\mathrm{O}$ and $\mathrm{S}$ (light blue circles); and (c) Sn (mustard triangles), $\mathrm{Zr}$ (green upside down triangles), Mo (purple squares), and V (gray circles) profiles. 
Revision Submitted to Mater. Charac.
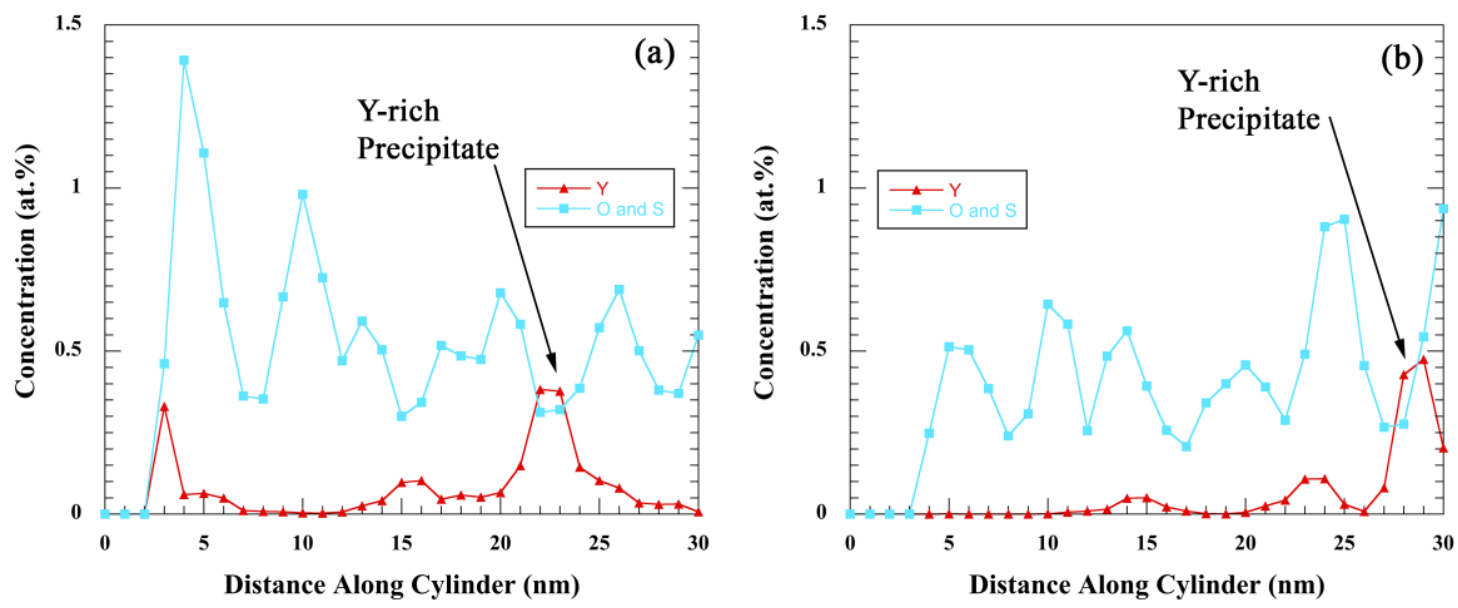

Figure 4. One-dimensional Y (red triangles) and $\mathrm{O}$ and $\mathrm{S}$ (blue circles) concentration profiles (at.\%) in (a) and (b) derived from two different 2-nm diameter analysis cylinders that illustrate $\mathrm{Y}$ enhancement (black arrows) corresponding to two different example Y-rich precipitates in the weld FZ from Fig. 1(a), and the associated local $\mathrm{O}$ and $\mathrm{S}$ distribution. 